\title{
Composição química e eficácia do óleo essencial e do extrato etanólico de Alpinia zerumbet sobre Staphylococcus aureus
}

\author{
Chemical composition and efficacy of essential oil and ethanol \\ extract of Alpinia zerumbet on Staphylococcus aureus
}

\author{
Karina Neoob de Carvalho Castro ${ }^{*}$, David Fernandes Lima², Luciene Costa Vasconcelos ${ }^{3}$, \\ Raimunda Cardoso Santos ${ }^{3}$, Alitiene Moura Lemos Pereira', Fabíola Helena dos Santos Fogaça', \\ Kirley Marques Canuto ${ }^{4}$, Edy Sousa de Brito ${ }^{4}$, Rodrigo Maciel Calvet ${ }^{5}$
}

RESUMO: O presente trabalho descreve a atividade antibacteriana do óleo essencial e do extrato etanólico das folhas de Alpinia zerumbet (colônia) sobre cepas de Staphylococcus aureus isoladas de vacas com mastite subclínica e cepas padrão ATCC 29213 e ATCC 25923, por meio do método de difusão em ágar. Foram utilizados 10 tratamentos contendo diferentes concentraçóes do óleo essencial e do extrato etanólico $\left(100,0 ; 50,0 ; 25,0 ; 12,5\right.$ e 6,3 mg. $\left.\mathrm{mL}^{-1}\right)$ e o grupo controle (álcool etílico a $50 \%$ e Tween a $1 \%)$. Os constituintes majoritários do óleo essencial foram $p$-cimeno (32,72\%), 1,8-cineol (24,05\%) e 4-terpineol (20,23\%), sendo esses determinados por cromatografia a gás acoplada a espectrometria de massas e cromatografia a gás com detector de ionização de chama (CG-EM/DIC). No extrato etanólico foi detectado o ácido elágico e três flavonoides: rutina, quercetina e campferol, por meio de cromatografia a líquido de alta eficiência acoplada a detector de arranjo de diodo (CLAE-DAD). Todas as cepas apresentaram sensibilidade aos tratamentos com óleo essencial e extrato etanólico. A melhor resposta foi obtida com o óleo essencial de $A$. zerumbet que, na concentração de $100 \mathrm{mg} \cdot \mathrm{mL}^{-1}$ proporcionou inibição total do crescimento bacteriano. Esses resultados sugerem o potencial antibacteriano do óleo essencial e do extrato etanólico de A. zerumbet no controle da mastite bovina.

PALAVRAS-CHAVE: Alpinia zerumbet; atividade antibacteriana; bovinos; planta medicinal.

\begin{abstract}
The present work describes the antibacterial activity of the essential oil and the ethanol extract from leaves of Alpinia zerumbet (colônia) on Staphylococcus aureus strains isolated from cows with subclinical mastitis and standard strains ATCC 29213 and ATCC 25923, using the agar diffusion method. Ten treatments containing different concentrations of essential oil and ethanol extract $\left(100.0 ; 50.0 ; 25.0 ; 12.5\right.$ and $\left.6.3 \mathrm{mg} \cdot \mathrm{mL}^{-1}\right)$ and the control group (50\% ethyl alcohol and $1 \%$ Tween solutions) were used for antimicrobial testing. The major constituents of the essential oil were $p$-cimeno $(32.72 \%), 1.8$-cineol $(24.05 \%)$ and 4-terpineol $(20.23 \%)$, which were determined by gas chromatographymass spectrometry and gas chromatography - flame ionization detector (CG-MS/FID). Ellagic acid and three flavonoids (rutin, quercetin and campferol) were detected in the ethanol extract by means of high performance liquid chromatography-photodiode array detector (HPLC-PDA). All strains showed sensitivity to the treatments with essential oil and the ethanol extract. The best response was obtained with $A$. zerumbet essential oil at a $100 \mathrm{mg} \cdot \mathrm{mL}^{-1}$, showing complete inhibition of bacterial growth. These results demonstrate the antibacterial potential of essential oil and ethanol extract of A. zerumbet in the control of bovine mastitis.
\end{abstract}

KEYWORDS: Alpinia zerumbet; antibacterial activity; bovine; medicinal plants.

\footnotetext{
'Embrapa Meio-Norte - Parnaíba (PI), Brasil.

${ }^{2}$ Universidade Federal do Vale do São Francisco - Paulo Afonso (BA), Brasil.

${ }^{3}$ Anidro Extrações do Brasil S.A. - Parnaíba (PI), Brasil.

${ }^{4}$ Embrapa Agroindústria Tropical - Fortaleza (CE), Brasil.

${ }^{5}$ Instituto Federal de Educação, Ciência e Tecnologia do Maranhão - Caxias (MA), Brasil.

*Autor correspondente: karina.castro@embrapa.br

Recebido em: 28/02/2014. Aceito em: 09/12/2015
} 


\section{INTRODUÇÃO}

A mastite é a doença mais importante em rebanhos leiteiros (FAGUNDes; Oliveira, 2004) e, em razão de sua alta prevalência, estima-se que possam ocorrer perdas entre 12 e $15 \%$ da produçáo leiteira brasileira (FONSECA; SANTOS, 2000). A mastite subclínica responde por até $95 \%$ dos casos de mastite em um rebanho e seu diagnóstico é realizado geralmente a campo por meio da prova do California Mastitis Test (CMT) (Fonseca; SAntos, 2000).

O principal agente causador da mastite em bovinos é o Staphylococcus aureus, que se destaca como o micro-organismo de tratamento mais difícil, devido à elevada resistência aos antibióticos (FAgundes; OliveIra, 2004). O aparecimento de cepas multirresistentes é favorecido pelo uso indiscriminado de antimicrobianos que, quando utilizados em animais de produção, pode levar ao acúmulo de resíduos nos alimentos, com sérias consequências para a saúde do consumidor (Mota et al., 2005). Portanto, faz-se necessária a descoberta de compostos novos e seguros para controle da mastite bovina (FonsECA et al., 2013).

O estudo de fitoterápicos tem sido considerado mundialmente importante, pela busca de substâncias menos tóxicas e mais eficazes contra resistência bacteriana (Оsтrosky et al., 2008). Muitas plantas medicinais já são utilizadas para o tratamento de animais (MARINHO et al., 2007). Algumas delas têm atividade contra um grande número de bactérias (BERTINI et al., 2005). Alpinia zerumbet (Pers.) B.L. Burtt \& R.M. Sm é uma espécie originária da Ásia, pertencente à família Zingiberaceae, e encontrada na literatura científica com as sinonímias de Alpinia speciosa K. Shum, Costus zerumbet Pers., Languas speciosa Small e Zerumbet speciosum J. C. Wendel (Lorenzi; SouZA, 2001). Essa planta é conhecida popularmente como colônia, sendo muito encontrada no Nordeste do Brasil, e utilizada como anti-hipertensiva, diurética e febrífuga (CorREA et al., 2010), havendo trabalhos que comprovam sua atividade antimicrobiana (VICTÓRIo et al., 2009).

O objetivo deste estudo foi avaliar a atividade antibacteriana do óleo essencial e do extrato etanólico de Alpinia zerumbet sobre cepas de Staphylococcus aureus, isoladas de mastite subclínica de vacas de um rebanho leiteiro e sobre cepas padrão ATCC.

\section{MATERIAIS E MÉTODOS}

As partes aéreas de Alpinia zerumbet (Pers.) B. L. Burtt \& R. M. Sm. foram coletadas na Fazenda Tabuleiros II da empresa Anidro do Brasil Extraçôes S.A., Parnaíba, Piauí (latitude 0301'27,5”S e longitude 41०44'53,5”W, a 35 m de altitude). As coletas foram realizadas no mês de julho de 2011, sempre no período da manhá. Uma exsicata do material botânico foi depositada no herbário da Embrapa Recursos Genéticos e Biotecnologia (CEN), sob o $\mathrm{n}^{\circ}$ de tombo 81.103.
O óleo essencial (OE) foi obtido a partir de folhas recém-colhidas de $A$. zerumbet, submetidas à destilação por arraste a vapor d'água (Simóes; Spitzer, 1999; Matos, 2009). Após a condensação dos vapores, o óleo essencial foi separado da fase aquosa, obtendo-se o hidrolato e o óleo essencial bruto. Para preparo do extrato etanólico (EE), folhas verdes de $A$. zerumbet foram secas em estufa de circulação forçada de ar a $45^{\circ} \mathrm{C}$ e, a seguir, trituradas em moinho de facas (peneira de $1 \mathrm{~mm}$ ). Após esse procedimento, $150 \mathrm{~g}$ do material foram submetidos à maceração a frio em etanol P.A., de acordo com Matos (2009).

A análise cromatográfica do $\mathrm{OE}$ de $A$. zerumbet foi realizada por cromatografia gasosa acoplada a espectrometria de massas (CG-EM) em cromatógrafo Varian CG-450/MS-240 (Palo Alto, EUA) com impacto de elétrons a $70 \mathrm{eV}$, coluna cromatográfica VF-5MS metilpolissiloxano (30 m x 0,25 $\mathrm{mm} \times 1,0 \mu \mathrm{m}$; Varian Inc.), modo de injeção com divisão de fluxo de 1:100, gás carreador hélio com fluxo de $1 \mathrm{~mL} \cdot \mathrm{min}^{-1}$, temperatura do injetor $250^{\circ} \mathrm{C}$ e temperatura da linha de transferência $250^{\circ} \mathrm{C}$. Programação do forno cromatográfico: temperatura inicial de $70^{\circ} \mathrm{C}$ com rampa de aquecimento de $4^{\circ} \mathrm{C}$. $\min ^{-1}$ até $180^{\circ} \mathrm{C}$, seguida por rampa de aquecimento de $10^{\circ} \mathrm{C}$. $\min ^{-1}$ até $250^{\circ} \mathrm{C}$. A identificação dos compostos foi realizada pela análise dos padróes de fragmentaçáo exibidos nos espectros de massas, sendo confirmada por comparação dos seus espectros de massas com aqueles presentes na base de dados fornecida pelo equipamento (NIST 287.324 compostos), bem como por meio da comparaçấo dos seus índices de retençấo com os de compostos conhecidos, obtidos por injeção de uma mistura de padróes contendo uma série homóloga de $n$-alcanos $\mathrm{C}_{7}-\mathrm{C}_{22}$, e dados da literatura (Adams, 2007; Nist Chemistry шЕввоOK, 2011). A análise por cromatografia gasosa acoplada com detector de ionização de chama (CG-DIC) foi realizada num instrumento Shimadzu QP-2010 Plus (Kioto, Japão), com detector de ionização por chama (DIC), coluna RTX-5 ( $30 \mathrm{~m} \times 0,25 \mathrm{~mm} \times 0,25 \mu \mathrm{m}$; Restek), modo de injeçáo com divisão de fluxo de $1: 30$, gás carreador nitrogênio com fluxo constante de $1,5 \mathrm{~mL} \cdot \mathrm{min}^{-1}$, temperatura do injetor $250^{\circ} \mathrm{C}$ e temperatura do detector $280^{\circ} \mathrm{C}$. As condiçóes de separaçấo foram as mesmas empregadas no CG-EM. A contribuição de cada composto volátil na mistura foi dada pela área relativa (\%) do seu respectivo pico no cromatograma, registrado por DIC.

A análise cromatográfica do $\mathrm{EE}$ de $A$. zerumbet foi realizada por eluição em um cartucho $\mathrm{C} 18$ de extração em fase sólida (500 mg, SampliQ, Agilent), utilizando-se como fase móvel água e metanol nas seguintes proporçôes de solvente orgânico: $0 \%$ (EE-F1); 25\% (EE-F2); 50\% (EE-F3); 75\% (EE-F4); 100\% (EE-F5). As fraçôes obtidas foram analisadas por cromatografia líquida de alta eficiência (CLAE), por meio de um cromatógrafo Varian 920-LC acoplado a um detector de arranjo de diodo (DAD) e munido de coluna de fase inversa (Microsorb $100 \mathrm{C} 18,250 \times 4,6 \mathrm{~mm}, 5 \mu \mathrm{m}$ ), termostatizada a $30^{\circ} \mathrm{C}$. A fase móvel foi constituída por $\mathrm{H}_{2} \mathrm{O}$ ultrapura (Milli-Q), acidificada com $0,1 \%$ de ácido fosfórico (Vetec, Rio de Janeiro) e metanol 
grau HPLC (Tedia). As separaçóes foram efetuadas com alíquotas de $20 \mu \mathrm{L}$, fluxo de $1 \mathrm{~mL} \cdot \mathrm{min}^{-1}$ e gradiente de eluição $0-95 \%$ $\mathrm{MeOH}(0-35 \mathrm{~min})$, seguido por corrida isocrática a $95 \%$ por 5 min. A identificação dos constituintes foi baseada no tempo de retenção e espectros de ultravioleta de 12 padrôes analíticos: ácido gálico, ácido elágico, ácido ferúlico, ácido o-cumárico, ácido $p$-hidroxibenzoico, ácido trans-cinâmico, ácido vanílico, catequina, rutina, quercetina, epicatequina e campferol. As amostras, padróes e solventes foram previamente filtradas em membranas de nylon de 0,45 $\mu \mathrm{m}$ (Millipore).

Para aquisição das amostras de bactérias, realizou-se a triagem dos tetos mamários de vacas mestiças girolando em lactação, pertencentes ao rebanho experimental da Embrapa Meio-Norte, Unidade de Execução de Pesquisa Parnaíba, por meio do CMT, conforme descrição de Schalm et al. (1971). Nesse rebanho, dois tetos, um de cada vaca, apresentaram reaçáo positiva, sendo identificados para a coleta das amostras, após lavagem com água e sabão, secagem com papel toalha e desinfecção do óstio do teto, utilizando-se álcool $70 \%$. Foram coletados $10 \mathrm{~mL}$ de leite por teto mamário em tubos de ensaio esterilizados e identificados, sendo, em seguida, acondicionados sob refrigeraçáo e encaminhados para o Laboratório de Bacteriologia da Embrapa Meio-Norte, Unidade de Execução de Pesquisa Parnaíba.

Para realização das análises microbiológicas, as amostras de leite das tetas das vacas positivas ao CMT foram homogeneizadas e alíquotas de $0,1 \mathrm{~mL}$ foram transferidas para placas de Petri contendo ágar Baird Parker (BP), ágar Nutriente e ágar Mac Conkey (Oxoid, U.K ${ }^{\circ}$ ). A seguir, as placas foram incubadas a $37^{\circ} \mathrm{C}$ por 24 horas. Após o crescimento microbiano, foi realizada a identificação das bactérias, por meio da observação das características morfológicas e microscópicas das colônias, utilizando-se a coloração de Gram (QuinN et al., 1994).

As colônias típicas e atípicas de Staphylococcus sp em ágar BP foram identificadas, transferidas para tubos de ensaio contendo caldo infusão de cérebro e coração e incubadas em estufa a $37^{\circ} \mathrm{C}$ por 24 horas. A seguir, foram realizados testes de coagulase livre (Plasma Coagulase EDTA, Coagu-Plasma LB, Laborclin, Brasil), provas de catalase e coloraçôes de Gram (Brasil, 2003). As provas de produção de acetoína, fermentação da glicose (aerobiose) e do manitol (aerobiose e anaerobiose) foram realizadas segundo MAC FADDIN (1980) e os materiais isolados foram classificados de acordo com BAIRDParker (1990) como S. aureus.

O estudo da atividade antibacteriana foi realizado por meio do teste de difusão em ágar, de acordo com as recomendaçóes da National Committee for Clinical Standards (NCCLS, 2003). Foram utilizadas cepas de $S$. aureus isoladas de duas vacas com mastite subclínica, denominadas isolado da vaca 1 (IV1) e isolado da vaca 2 (IV2), e cepas padrão de $S$. aureus ATCC 25923 (CP 25) e ATCC 29213 (CP 29). Foram preparadas suspensóes de cada cepa em 5,0 mL de solução salina estéril a 0,85\% $(\mathrm{p} / \mathrm{v})$, padronizadas e comparadas visualmente à escala $0,5 \mathrm{de}$
Mc Farland (BioMéreux ${ }^{\oplus}$ ). Com o auxílio de um swab estéril, a suspensão bacteriana foi semeada nas superfícies de placas para cultura de células com seis poços contendo ágar Muller-Hinton $\left(M_{e r c k}\right)$. Em seguida, procedeu-se a perfuraçáo de orifícios de 5,0 mm de diâmetro nos centros dos poços, com auxílio de uma ponteira estéril. Em cada orifício foram inoculados $100 \mu \mathrm{L}$ das diferentes concentraçôes (100,0; 50,0; 25,0; 12,5 e 6,3 mg.mL $\left.\mathrm{mL}^{-1}\right)$ do OE e do EE ou controle (álcool etílico a 50\% e Tween a $1 \%)$ com auxílio de micropipeta. Posteriormente, cada placa foi incubada a $37^{\circ} \mathrm{C}$ por $24 \mathrm{~h}$. A avaliaçấo da atividade antimicrobiana foi realizada medindo-se os halos de inibição de crescimento bacteriano formados ao redor dos orifícios. Todos os ensaios foram feitos em quadruplicata.

Como parâmetro para a atividade antimicrobiana do $\mathrm{OE}$ e do EE de $A$. zerumbet, foram utilizados os padrōes de sensibilidade adotados por PonCE et al. (2003). Assim, a atividade das diferentes concentraçóes do OE e do EE foi classificada de acordo com o tamanho do halo de inibiçãa, como não sensível (-), sensível (+), muito sensível (++) e extremamente sensível (+++), para diâmetros respectivos de $\leq 8 ; 9$ a 14; 15 a 19; e $\geq 20 \mathrm{~mm}$.

$\mathrm{Na}$ análise estatística foi utilizado um delineamento inteiramente casualizado, em esquema fatorial $2 \times 6 \times 4$, constituído pelo extrato etanólico e óleo essencial, em 6 concentraçôes (incluindo o controle), sobre 4 cepas de $S$. aureus, com 4 repetiçóes. O resultado final, determinado pela média aritmética dos halos de inibição $(\mathrm{mm})$, foi submetido à análise de variância $(\mathrm{p}<0,01)$ e teste de Tukey $(\mathrm{p}<0,05)$, usando-se o programa ASSISTAT (Silva; Azevedo, 2009).

\section{RESULTADOS E DISCUSSÃO}

As análises de CG-EM/DIC do OE das folhas de $A$. zerumbet permitiram a identificaçấo de 23 compostos voláteis, correspondendo a aproximadamente $98,7 \%$ da constituição química, em termos de área relativa dos picos (Tabela 1). O OE de $A$. zerumbet foi constituído basicamente por monoterpenos (21), sendo $p$-cimeno (32,72\%), 1,8-cineol (24,05\%) e 4-terpineol $(20,23 \%)$ os constituintes majoritários, além de 2 sesquiterpenos. Segundo dados da literatura, 1,8-cineol e 4-terpineol são comumente os principais componentes do óleo essencial dessa planta (Zoghbi et al., 1999), enquanto que $p$-cimeno, em teores significativos, somente foi detectado em espécies cultivadas na ilha de Okinawa, Japáo (Murakami et al., 2009).

Monoterpenos oxigenados são indicados como os principais responsáveis pela atividade antimicrobiana de óleos extraídos de $A$. zerumbet (VICTÓRIO et al., 2009). JANSSEN; SCHefFER (1985) е Маталуон et al. (2007) atribuem a 4-terpineol e 1,8-cineol a capacidade de inibir vários micro-organismos agindo, esse último, também contra $S$. aureus (GaCHKar et al., 2007). Segundo Oonmetta-Aree et al. (2006), a ação antimicrobiana pode estar relacionada à presença de sesquiterpenos 
em folhas, raízes e flores de espécies da família Zingiberaceae. Por sua vez, há evidências de que o $p$-cimeno interfira em atividade antimicrobiana, quando junto a outros constituintes, agindo por meio de um efeito sinérgico (PASTER et al., 1995). Mesmo aquelas substâncias que estão em pequenas proporçóes na planta podem ser responsáveis pela atividade biológica (LimA et al., 2014), dependendo do potencial de ação da mesma e de seu sinergismo com as demais substâncias do óleo. Há uma ampla variedade de compostos com atividade antimicrobiana no OE de A. Zerumbet (Victório et al., 2009), o que indica seu grande potencial para desenvolvimento de novas drogas.

Tabela 1. Percentagem dos constituintes químicos do óleo essencial de Alpinia zerumbet.

\begin{tabular}{|c|c|c|}
\hline Componente & IK & $\begin{array}{c}\text { Área relativa } \\
(\%)^{*}\end{array}$ \\
\hline N.I. & 902 & 0,09 \\
\hline$\alpha$-tujeno & 934 & 2,57 \\
\hline$\alpha$-pineno & 943 & 1,54 \\
\hline N.I. & 953 & 0,07 \\
\hline canfeno & 960 & 0,29 \\
\hline sabineno & 982 & 5,02 \\
\hline$\beta$-pineno & 987 & 2,37 \\
\hline mirceno & 994 & 0,66 \\
\hline$\alpha$-terpineno & 1024 & 0,06 \\
\hline$p$-cimeno & 1034 & 32,72 \\
\hline limoneno & 1037 & 2,09 \\
\hline 1,8-cineol & 1041 & 24,05 \\
\hline$\gamma$-terpineno & 1066 & 0,68 \\
\hline sabineno hidrato & 1075 & 0,15 \\
\hline$\alpha$-terpinoleno & 1095 & 0,28 \\
\hline cis- $\beta$-terpineol & 1102 & 1,01 \\
\hline cis- $p$-ment-2-en-1-ol & 1129 & 0,65 \\
\hline trans-p-ment-2-en-1-ol & 1148 & 0,51 \\
\hline N.I. & 1175 & 0,20 \\
\hline 4-terpineol & 1186 & 20,23 \\
\hline$p$-cimen-8-ol & 1191 & 0,34 \\
\hline$\alpha$-terpineol & 1197 & 1,16 \\
\hline trans-piperitol & 1214 & 0,23 \\
\hline N.I. & 1263 & 0,43 \\
\hline acetato de bornila & 1293 & 0,17 \\
\hline N.I. & 1297 & 0,16 \\
\hline N.I. & 1306 & 0,17 \\
\hline$\beta$-cariofileno & 1429 & 0,24 \\
\hline N.I. & 1569 & 0,16 \\
\hline
\end{tabular}

IK: Índice de Kovats exibidos pelos compostos em coluna RTX; *área relativa do pico no cromatograma obtido por cromatografia gasosa acoplada com detector de ionização de chama; N.I.: substância não identificada.
As análises de CLAE-DAD revelaram que o EE das folhas de $A$. zerumbet era rico em compostos fenólicos. As fraçôes derivadas continham o ácido elágico e ao menos três flavonoides: rutina, quercetina e campferol (Tabela 2). No extrato aquoso das folhas de A. zerumbet, Mpalantinos et al. (1998) identificaram a presença de rutina e derivados glicosilados de campferol, além de catequinas. Por sua vez, no extrato de acetato de etila das folhas de $A$. zerumbet, ElzaAwely et al. (2007) encontraram vários ácidos fenólicos, tais como ácido siríngico, ácido ferúlico, ácido $p$-cumárico, ácido $p$-hidroxi-benzoico, ácido cinâmico, ácido vanílico, enquanto que somente o ácido elágico foi detectado no presente trabalho. Essas diferenças nos constituintes dos óleos e extratos podem ser atribuídas à origem da planta e época de colheita, pois a composição das substâncias é dependente de fatores como luminosidade, calor, constituiçấo do solo e umidade (LAPA et al., 1999).

Extratos de diversas espécies medicinais, que contêm flavonoides, possuem ação contra S. aureus (PINHo et al., 2012). Alguns trabalhos relatam a capacidade dos flavonoides de inibir a função da membrana citoplasmática, com consequente destruição da integridade celular das bactérias, além da inibição do metabolismo energético e inibição da síntese de DNA das mesmas. Os flavonoides detectados neste trabalho são reportados por possuírem ação antimicrobiana (Cushnie; Lamb, 2005). Além disso, a atividade antimicrobiana determinada pelo ácido elágico já foi descrita por Chung (1998) e VATtem; Shetty (2005).

A atividade antibacteriana das cinco concentraçóes do $\mathrm{OE}$ e do EE das folhas de $A$. zerumbet contra as cepas de $S$. aureus é apresentada na Tabela 3. O maior halo de inibição $(35 \mathrm{~mm})$ foi obtido por ação do OE contra a cepa IV2, havendo inibição total do crescimento bacteriano induzida pela concentração de $100 \mathrm{mg} . \mathrm{mL}^{-1}$. Esses resultados foram superiores aos apresentados por Lовато et al. (1989) que, ao avaliarem o OE das folhas de $A$. zerumbet sobre $S$. aureus, obtiveram halos de inibição que variaram de 0,7 a $14 \mathrm{~mm}$. Essa diferença de açấo pode ser atribuída à origem diversa, que determina diferença na composição dos mesmos (LAPA et al., 1999).

Os halos de inibição do OE foram significativamente superiores $(\mathrm{p}<0,01)$ em relação àqueles induzidos pelo $\mathrm{EE}$ de $A$. zerumbet diante das cepas CP25 (100 mg.mL-1), IV1 $\left(100,0 ; 50,0\right.$ e $12,5 \mathrm{mg} \cdot \mathrm{mL}^{-1}$ ) e IV2 (em todas as concentrações). De forma geral, o OE exibiu maior atividade do que o EE (Tabela 3), sugerindo que haja maior concentraçáo de compostos químicos ativos contra o $S$. aureus no $\mathrm{OE}$ do que no EE de $A$. zerumbet. Resultados similares foram observados, cuja ação de $\mathrm{OE}$ se sobrepóe aos de extratos obtidos com a mesma espécie medicinal, diante de S. aureus (Vukovic et al., 2007; GONÇALVES et al., 2008).

De acordo com a classificação de PONCE et al. (2003), na concentração de $100 \mathrm{mg} \cdot \mathrm{mL}^{-1}$ todas as cepas de $S$. aureus foram extremamente sensíveis (halo de $20 \mathrm{~mm}$ ) ao $\mathrm{OE} \mathrm{de}$ A. zerumbet, exceto a cepa CP29, que foi muito sensível (halo de 15 a $19 \mathrm{~mm}$ ), enquanto que, mesmo com a concentraçáo 
reduzida para $50 \mathrm{mg} \cdot \mathrm{mL}^{-1}$, as cepas IV1 e IV2 permaneceram extremamente sensíveis (halo de $20 \mathrm{~mm}$ ) (Tabela 3). Todas as cepas apresentaram sensibilidade ao EE de A. zerumbet (halo de 9 a $14 \mathrm{~mm}$ ) na concentração de $50 \mathrm{mg} \cdot \mathrm{mL}^{-1}$, enquanto que as cepas CP25 e IV2 foram muito sensíveis (halo de 15 a $19 \mathrm{~mm}$ ), quando utilizada a concentraçáo de $100 \mathrm{mg} \cdot \mathrm{mL}^{-1}$. Esses dados confirmam o potencial do OE e do EE no controle de $S$. aureus.

A ação antibacteriana de extratos de plantas do gênero Alpinia pode variar amplamente de acordo com a espécie, partes

Tabela 2. Composição química das frações derivadas do extrato etanólico das folhas de $A$. zerumbet baseada no tempo de retenção e nas absorções máximas nos espectros de ultravioleta determinados por cromatografia líquida de alta eficiência acoplada a um detector de arranjo de diodo.

\begin{tabular}{|c|c|c|c|c|c|c|c|}
\hline \multirow{2}{*}{ Compostos } & TR & \multirow{2}{*}{ I (nm) } & EE-F1 & EE-F2 & EE-F3 & EE-F4 & EE-F5 \\
\hline & (min) & & $0 \%$ & $25 \%$ & $50 \%$ & $75 \%$ & $100 \%$ \\
\hline Ácido gálico & 10,0 & $217 ; 271$ & ND & ND & ND & ND & ND \\
\hline Catequina & 15,3 & 278 & ND & ND & ND & ND & ND \\
\hline Ácido $p$-hidroxi-benzóico & 16,3 & 254,327 & ND & ND & ND & ND & ND \\
\hline Ácido vanílico & 17,5 & $217 ; 261 ; 291$ & ND & ND & ND & ND & ND \\
\hline Ácido ferúlico & 21,0 & $236 ; 315$ & ND & ND & ND & ND & ND \\
\hline Rutina & 23,2 & $257 ; 356$ & ND & ND & + & + & + \\
\hline Ácido o-cumárico & 23,4 & $275 ; 324$ & ND & ND & ND & ND & ND \\
\hline Ácido elágico & 24,4 & $247 ; 366$ & + & ND & + & + & + \\
\hline Ácido trans-cinâmico & 26,7 & $215 ; 275$ & ND & ND & ND & ND & ND \\
\hline Quercetina & 26,9 & 255,372 & ND & ND & + & + & + \\
\hline Campferol & 28,9 & $241 ; 266 ; 305$ & ND & + & + & + & ND \\
\hline Epicatequina & 32,6 & 267 & ND & ND & ND & ND & ND \\
\hline
\end{tabular}

TR: tempo de retração; I: absorções máximas nos espectros de ultravioleta; EE-F: frações do extrato etanólico; ND: não detectado.

Tabela 3. Média e desvio padrão dos halos de inibição de colônias* de Staphylococcus aureus determinados pela ação do óleo essencial e do extrato etanólico de Alpinia zerumbet.

\begin{tabular}{|c|c|c|c|c|}
\hline \multirow{2}{*}{$\begin{array}{l}\text { Tratamentos e } \\
\text { concentrações }\left(\mathrm{mg} \cdot \mathrm{mL}^{-1}\right)\end{array}$} & \multicolumn{4}{|c|}{ Médias $^{* *} \pm \mathrm{DP}(\mathrm{mm})$} \\
\hline & CP25 & CP29 & IV 1 & IV2 \\
\hline \multicolumn{5}{|l|}{ Óleos essenciais } \\
\hline 100,0 & $23,3 \pm 1,3^{a c}$ & $16,0 \pm 2,4^{a D}$ & $27,0 \pm 1,5^{\mathrm{aB}}$ & $35,0 \pm 0,0^{\mathrm{aA}}$ \\
\hline 50,0 & $17,5 \pm 2,4^{\mathrm{bc}}$ & $12,3 \pm 0,6^{\mathrm{bD}}$ & $22,5 \pm 0,7^{\mathrm{bB}}$ & $25,0 \pm 2,8^{\mathrm{bA}}$ \\
\hline 25,0 & $14,4 \pm 0,7^{\mathrm{cdB}}$ & $8,0 \pm 2,0^{c c}$ & $14,3 \pm 1,8^{\mathrm{cB}}$ & $18,8 \pm 2,4^{\mathrm{cA}}$ \\
\hline 12,5 & $9,8 \pm 1,5^{\mathrm{eB}}$ & $5,0 \pm 0,0^{c c}$ & $10,8 \pm 1,2^{\mathrm{dB}}$ & $14,9 \pm 2,8^{\text {deA }}$ \\
\hline 6,3 & $5,0 \pm 0,0^{\mathrm{AB}}$ & $5,0 \pm 0,0^{c B}$ & $7,2 \pm 1,5^{\text {ев }}$ & $10,3 \pm 1,0^{\mathrm{fA}}$ \\
\hline Controle & $5,0 \pm 0,0^{f A}$ & $5,0 \pm 0,0^{c A}$ & $5,0 \pm 0,0^{e A}$ & $5,0 \pm 0,0^{g A}$ \\
\hline \multicolumn{5}{|l|}{ Extrato etanólico } \\
\hline 100,0 & $18,1 \pm 1,0^{\mathrm{bA}}$ & $14,6 \pm 1,4^{\mathrm{abB}}$ & $14,3 \pm 0,5^{\mathrm{cB}}$ & $16,0 \pm 0,7^{\mathrm{cdAB}}$ \\
\hline 50,0 & $15,3 \pm 0,9^{\mathrm{bcA}}$ & $11,9 \pm 1,6^{\mathrm{bB}}$ & $12,3 \pm 1,0^{\mathrm{cdB}}$ & $13,4 \pm 0,7^{\mathrm{de} A \mathrm{E}}$ \\
\hline 25,0 & $12,9 \pm 0,5^{\mathrm{cdA}}$ & $7,7 \pm 3,4^{\mathrm{cB}}$ & $10,5 \pm 1,3^{\mathrm{dA}}$ & $12,6 \pm 0,6^{\mathrm{efA}}$ \\
\hline 12,5 & $11,5 \pm 0,6^{\mathrm{deA}}$ & $5,0 \pm 0,0^{c B}$ & $5,0 \pm 0,0^{e B}$ & $5,0 \pm 0,0^{g B}$ \\
\hline 6,3 & $8,5 \pm 2,4^{\mathrm{eA}}$ & $5,0 \pm 0,0^{c B}$ & $5,0 \pm 0,0^{\mathrm{eB}}$ & $5,0 \pm 0,0^{g B}$ \\
\hline Controle & $5,0 \pm 0,0^{f A}$ & $5,0 \pm 0,0^{c A}$ & $5,0 \pm 0,0^{\mathrm{eA}}$ & $5,0 \pm 0,0^{g A}$ \\
\hline
\end{tabular}

*Área de inibição inclui $5 \mathrm{~mm}$ de diâmetro do poço; **médias de quadruplicatas; DP: desvio padrão; CP25: cepa ATCC 25923; CP29: cepa ATCC 292 13; IV 1: isolado da vaca 1; IV2: isolado da vaca 2; médias seguidas pelas mesmas letras minúsculas na coluna e maiúsculas na linha não diferem estatisticamente entre si; teste de Tukey com 95\% de significância. 
da planta, origem, método de extraçáo e solvente utilizado. Esses fatores podem interferir na composição química e proporção de metabólitos secundários dos extratos (CzELUSNIAK et al., 2012). Extratos hidroalcoólicos das raízes de Alpinia officinarum determinaram ação sobre $S$. aureus, proporcionalmente superior àquela induzida pelo EE de $A$. zerumbet (SRIvidya et al., 2010). Extratos metanólicos e aquosos de Alpinia allughas e Alpinia calcarata induziram maiores inibiçôes sobre $S$. aureus, quando preparados a partir das raízes em comparação com aqueles produzidos com folhas das mesmas espécies (Bhunia; Mondal, 2012). Por outro lado, os autores avaliaram também a ação de extratos de Alpinia galanga e obtiveram melhores resultados com as folhas, em comparaçáo àqueles preparados com as raízes. É possível que em determinadas espécies de Alpinia haja maior concentração de substâncias ativas contra $S$. aureus nas raízes. No entanto, a elaboraçáo de extratos a partir de folhas tem a vantagem de promover a sobrevivência da planta (PINHo et al., 2012), sendo, portanto, uma prática sustentável que deve ser estimulada.
Novos estudos devem ser realizados para avaliar o potencial do OE e do EE das folhas de $A$. zerumbet em formulações para infusão intramamária, em modelos com bovinos.

\section{CONCLUSÃO}

$\mathrm{O} \mathrm{OE}$ e o EE das folhas de $A$. zerumbet possuem ação significativa contra Staphylococcus aureus, portanto, possuem importante potencial como fonte de novos compostos antibacterianos para o controle da mastite bovina.

\section{AGRADECIMENTOS}

Os autores agradecem a Antônio Almeida de Paz Neto e João Batista Alves de Souza pela colaboração nos experimentos.

| | | | | | | | | | | | | | | | | | | | | | | | | | | | | | | | | | | | | | | | | | | | | | | | | | | | | | | | | | | | | | | | | | | | | | | | | | | | | | | | | | | | | | | | | | | | | | | | | | | | | | | | | | | | | | | | | | | | | | | | | | | | | | | | | | | | | | | | | | | | | | | | | | | | | | | | | | | | | | | | | | | | | | | | | | | | | | | | | | | | | | | | | | | | | | | | | | | | | | | | | | | | | | | REFERÊNCIAS

ADAMS, R.P. Identification of essential oil components by gas chromatography mass spectrometry. 4. ed. Carol Stream: Allured Publ. Corp, 2007. 469p.

BAIRD-PARKER, A.C. The Staphylococci: an introduction. Journal for Applied Bacteriology symposium series, v. 19, p.1S-8S, 1990.

BERTINI, L.M.; PEREIRA, A.F.; OLIVEIRA, C.L.L.; MENEZES, E.A.; MORAIS, S.M.; CUNHA, F.A.; CAVALCANTI, E.S.B Perfil de sensibilidade de bactérias frente a óleos essenciais de algumas plantas do nordeste do Brasil. Infarma, v. 17, n.3-4, p.80-82, 2005.

BHUNIA, D.; MONDAL, A.K. Antibacterial Activity of Alpinia L. (Zingiberaceae) from Santal and Lodha Tribal Areas of Paschim Medinipur District in Eastern India. Advances in Bioresearch, v.3, n. 1, p.54-63, 2012.

BRASIL. Ministério da Agricultura, Pecuária e Abastecimento. Instrução normativa $\mathrm{n}^{\circ} 62$, de 26 de agosto de 2003 . Oficializa os métodos analíticos oficiais para análises microbiológicas para controle de produtos de origem animal e água. Diário Oficial da União, Brasília, 18 de setembro de 2003.

CHUNG, J.G. Inhibitory actions of ellagic acid on growth and arylamine $\mathrm{N}$-acetyltransferase activity in strains of Helicobacter pylori from peptic ulcer patients. Microbios, v.93, n.375, p.1 15-127, 1998.

CORREA, A.J.C.; LIMA, C.E.; COSTA, M.C.C.D. Alpinia zerumbet (Pers.) B.L. Burtt \& R. M. Sm. (Zingiberaceae): levantamento de publicações nas áreas farmacológica e química para o período de 1987 a 2008. Revista Brasileira de Plantas Medicinais, v. 12 , n. 1, p.113-119, 2010.

CUSHNIET.P.; LAMB, A.J. Antimicrobial activity of flavonoids. International Journal of Antimicrobial Agents, v.26, n.5, p.343-356, 2005.
CZELUSNIAK, K.E.; BROCCO, A.; PEREIRA, D.F.; FREITAS, G.B.L. Farmacobotânica, fitoquímica e farmacologia do Guaco: revisão considerando Mikania glomerata Sprengel e Mikania laevigata Schulyz Bip. ex Baker. Revista Brasileira de Plantas Medicinais, v.14, n.2, p.400-409, 2012.

ELZAAWELY, A.A.; XUAN, T.D.; TAWATA, S. Essential oils, kava pyrones and phenolic compounds from leaves and rhizomes of Alpinia zerumbet (Pers.) B.L. Burtt. \& R.M. Sm. and their antioxidant activity. Food Chemistry, v.103, n.2, p.486-494, 2007.

FAGUNDES, H.; OLIVEIRA, C.A.F. Infecções intramamárias causadas por Staphylococcus aureus e suas implicações em saúde pública. Ciência Rural, Santa Maria, v.34, n.4, p.1315-1320, 2004.

FONSECA, L.F.L.; SANTOS, M.V. Qualidade do leite e controle de mastite. São Paulo: Lemos Editorial, 2000. 175p.

FONSECA, A.P.; ESTRELA, F.T.; MORAES, T.S.; CARNEIRO, L.J.; BASTOS, J.K.; SANTOS, R.A.; AMBRÓSIO, S.R.; MARTINS, C.H.G.; VENEZIANI, R.C.S. In vitro antimicrobial activity of plant-derived diterpenes against bovine mastitis bacteria, Molecules, v. 18, n.7, p.7865-7872, 2013.

GACHKAR, L.; YADEGARI, D.; REZAEI, M.B.; TAGHIZADEH, M.; ASTANEH, S.A.; RASOOLI, I. Chemical and biological characteristics of Cuminum cyminum and Rosmarinus officinalis essential oils. Food Chemistry, v. 102, n.3, p.898-904, 2007.

GONÇALVES, F.A.; ANDRADE NETO, M.; BEZERRA, J.N.S.; MACRAE, A.; SOUSA, O.V.; FONTELES-FILHO, A.A.; VIEIRA, R.H.S.F. Antibacterial activity of guava, Psidium guajava Linnaeus, leaf extracts on diarrhea-causing enteric bacteria isolated from Seabob shrimp, Xiphopenaeus kroyeri (Heller). Revista do Instituto de Medicina Tropical de São Paulo, v.50, n. 1, p.11-15, 2008. 
JANSSEN, A.M.; SCHEFFER, J.J. Acetoxychavicol acetate, an antifungal component of Alpinia galanga. Planta Médica, v.51, n.6, p.507-511, 1985.

LAPA, A.J. GOSMANN, G.; MELLO, J.C.P.; MENTZ, L.A.; PETROVICK,; P.R. Farmacologia e toxicologia de produtos naturais. In: SIMÕES, C.M.O.; SCHENKEL, E.P.; GOSMANN, G.; MELLO, J.C.P.; MENTZ, L.A.; PETROVICK, P. R. (eds). Farmacognosia: da planta ao medicamento. Porto Alegre: UFRGS, 1999. p.181-196.

LIMA, A.S.; SOUSA FILHO, J.G.M.; PEREIRA, S.G.; GUILLON, G.M.S.P.; SANTOS, L.S.; COSTA JUNIOR, L.M. Acaricide activity of different extracts from Piper tuberculatum fruits against Rhipicephalus microplus. Parasitology Research, v. 113, n.1, p. 107-112, 2014.

LOBATO, A.M.; RIBEIRO, A.; PINHEIRO, M.F.S.; MAIA, J.G.S. Atividade antimicrobiana de óleos essenciais da Amazônia. Acta Amazônica, v.19, n.1, p.355-363, 1989.

LORENZI, H.; SOUZA, H.M. Plantas ornamentais no Brasil: arbustivas, herbáceas e trepadeiras. 3a.ed. São Paulo: Instituto Plantarum, 2001. 1067p.

MAC FADDIN, J.F. Biochemical test for identification of medical bacteria. 2nd ed. Baltimore: Williams \& Wilkins, 1980. 527p.

MARINHO M.L.; ALVES, M.S.; RODRIGUES, M.L.C.; ROTONDANO, T.E.F.; VIDAL I.F.; SILVA, W.W.; ATHAYDE, A.C.R. A utilização de plantas medicinais em medicina veterinária: um resgate do saber popular. Revista Brasileira de Plantas Medicinais, v.9, n.3, p.64-69, 2007.

MATASYOH, J.C.; KIPLIMO, J.J.; KARUBIU, N.M.; HAILSTORKS, T.P. Chemical composition and antimicrobial activity of essential oil of Tarchonanthus camphorates. Food Chemistry, v.101, n.3, p. $1183-1187,2007$.

MATOS, F.J.A. Introdução à fitoquímica experimental. 3a.ed. Fortazela: UFC, 2009. 141 p. 2009.

MOTA, R.A.; SILVA, K.P.C.; FREITAS, M.F.L.; PORTO, W.J.N.; SILVA, L.B.G. Utilização indiscriminada de antimicrobianos e sua contribuição a multirresitência bacteriana. Brazilian Journal of Veterinary Research and Animal Science, v.42, n.6, p.465-470, 2005.

MPALANTINOS, M.A.; SOARES DE MOURA, R.; PARENTE, J.P.; KUSTER, R.M. Biologically active flavonoids and kava pyrones from the aqueous extract of Alpinia zerumbet. Phytotherapy Research, v.12, n.6, p.442-444, 1998.

MURAKAMI, S.; LI, W.; MATSUURA, M.; SATOU, T.; HAYASHI, S.; KOIKE, K. Composition and seasonal variation of essential oil in Alpinia zerumbet from Okinawa Island. Journal of Natural Medicines, v.63, n.2, p.204-208, 2009.

NCCLS. NATIONAL COMMITTEE FOR CLINICAL LABORATORY STANDARDS. Methods for dilution antimicrobial susceptibility tests for bacteria that grow aerobically. Approved standard. 6th ed. Wayne: NCCLS, 2003.

NIST CHEMISTRY WEBBOOK. 2011. Disponível em: <http:// webbook.nist.gov/chemistry>. Acesso em: 13 out. 2013.
OONMETTA-AREE, J.; SUZUKI, T.; GASALUCK, P.; EUMKEB, G. Antimicrobial properties and action of galangal (Alpinia galanga Linn.) on Staphylococcus aureus. LWT - Food Science and Technology, v.39, n.10, p.1214-1220, 2006.

OSTROSKY, E.A.; MIZUMOTO, M.K.; LIMA, M.E.L.; KANEKO, T.M.; NISHIKAWA, S.O.; FREITAS, B.R. Métodos para avaliação da atividade antimicrobiana e determinação da concentração mínima inibitória (CMI) de plantas medicinais. Revista Brasileira de Farmacognosia, v.18, n.2, p.301-307, 2008.

PASTER, N.; MENASHEROV, M.; RAVID, U.; JUVEN, B. Antifungal activity of oregano and thyme essential oils applied as fumigants against fungi attacking stored grain. Journal of Food Protection, v.58, n. 1, p.81-85, 1995.

PINHO, L.; SOUZA, P.N.S.; SOBRINHO, E.M.; ALMEIDA, A.C.; MARTINS, E.R. Atividade antimicrobiana de extratos hidroalcoólicos das folhas de alecrim-pimenta, aroeira, barbatimão, erva baleeira e do farelo da casca de pequi. Ciência Rural, Santa Maria, v.42, n.2, p.326-331, 2012.

PONCE, A.G.; FRITZ, R.; DELVALLE, C.; ROURA, S.L. Antimicrobial activity of essential oils on native microbial population of organic Swiss Chard. Lebensmittel-Wissenschaft \& Technologie, v.36, n.7, p.679-684, 2003.

QUINN, P.J.; CARTER, M.E.; MARKEY, B.K.; CARTER, G.R. Clinical veterinary microbiology. London: Wolf, 1994. 648p.

SCHALM, O.W.; CARROL, E.J.; JAIN, N.C. Bovine mastitis. Philadelphia: Lea and Febiger, 1971. Chap. 11, p.249-282.

SILVA, F.A.S.; AZEVEDO, C.A.V. Principal components analysis in the software Assistat-Statistical Attendance. In: WORLD CONGRESS ON COMPUTERS IN AGRICULTURE, 7., 2009, Orlando. Proceedings... Reno: American Society of Agricultural and Biological Engineers, 2009. CD-ROM.

SIMÕES, C.M.; SPITZER, V. Farmacognosia: da planta ao medicamento. Rio Grande do Sul: Editora da Universidade Federal do Rio Grande do Sul, 1999. $821 \mathrm{p}$.

SRIVIDYA, A.R.; Dhanabal, s.p.; misra, v.k.; suja, g. Antioxidant and antimicrobial activity of Alpinia officinarum. Indian Journal of Pharmaceutical Science, v.72, n. 1, p.145-148, 2010.

VATTEM, D.A.; SHETTY, K. Biological functionality of ellagic acid: a review. Journal of Food Biochemistry, v.29, n.3, p.234-266, 2005.

VICTÓRIO, C.P.; ALVIANO, D.S.; ALVIANO, C.S.; LAGE, C.L.S. Chemical composition of the fractions of leaf oil of Alpinia zerumbet (Pers.) B.L. Burtt \& R.M. Sm. and antimicrobial activity. Revista Brasileira de Farmacognosia, v. 19, n.3, p.697-701, 2009.

VUKOVIC, N.; MILOSEVIC, T.; SUKDOLAK, S.; SOLUJIC, S. Antimicrobial activities of essential oil and methanol extract of Teucrium montanum. Evidence-Based of Complementary Alternative Medicine, v.4, suppl.1, p.17-20, 2007.

ZOGHBI, M.G.B.; ANDRADE, E.H.A.; MAIA, J.G.S. Volatile constituents from leaves and flowers of Alpinia speciosa $\mathrm{K}$. Schum. and $A$. pupurata (Viell.) Schum. Flavour and Fragrance Journal, v.14, n.6, p.411-414, 1999. 